\title{
Ernesto La Padula en Córdoba: peronismo y ciudad, 1946-1955/
}

\author{
Ernesto La Padula in Cordoba: \\ Peronismo and the City, 1946-1955
}

Juan Sebastián Malecki

ORCID iD: http://orcid.org/0000-0002-3699-6175

Universidad Nacional de Córdoba - CONICET

\begin{abstract}
En Córdoba, durante el decenio peronista (1946-1955) se llevaron adelante una serie de emprendimientos urbano-arquitectónicos que, en conjunto, implicaron una importante modernización de la estructura social y urbana de la ciudad, cuyo impacto se prolongaría hasta la década del setenta. Para analizar las políticas urbanas implementadas, nos centraremos en la trayectoria del italiano Ernesto La Padula y en el Plan Regulador de su autoría, lo que nos permitirá establecer los contextos que las posibilitaron, así como indagar en los debates disciplinares del urbanismo y la arquitectura de las que se nutrieron.

Palabras clave: Historia Urbana; Peronismo; Córdoba; La Padula.

During the Peronista Government (1946-1955), a group of urban and architectural projects were taken that, as the whole, implied a modernization of the social and urban structure of Cordoba which lasted until the seventies. In order to analyze the urban policies developed during those years, I will focus on the trajectory of the Italian Ernesto La Padula and the Master Plan of his authorship. This will allow me to indicate the contexts relevant to those policies as well as the urban and architectural debates that were on their basis.
\end{abstract}

KeYwords: Urban History; Peronismo; Cordoba; La Padula.

Copyright: (C) 2018 CSIC. Este es un artículo de acceso abierto distribuido bajo los términos de la licencia de uso y distribución Creative Commons Reconocimiento 4.0 Internacional (CC BY 4.0). 


\section{Presentación}

En el ciclo de modernización y radicalización que se dio en Argentina entre las décadas de 1950 y 1970, la ciudad de Córdoba se constituyó en una referencia central para ambos procesos, ya sea por la instalación de las industrias automotrices (IKA y Fiat) a mediado de los cincuenta o por la revuelta urbana de 1969 conocida como el Cordobazo. Pero mientras contamos con investigaciones que abordan el crecimiento industrial, la consolidación de un vigoroso movimiento obrero y la inusitada conflictividad social que se vivió entre los sesenta y setenta, todavía no tenemos estudios que analicen los cambios producidos en la propia ciudad. ${ }^{1}$ Justamente, esta no solo fue el «escenario» que hizo posible aquellos procesos, sino que también experimentó un intenso proceso de transformación urbana que llevó a que en menos de treinta años una misma generación pudiera ver ante sus ojos cómo pasaba de ser una tranquila capital provincia a una dinámica ciudad industrial, convirtiéndose en una de las ciudades argentinas de mayor crecimiento. Pero al analizar los procesos urbanos que se dieron en Córdoba, se vuelve necesaria una reconsideración de las periodizaciones corrientes ${ }^{2}$ - que suelen señalar el comienzo del ciclo modernizador con el derrocamiento de Perón en 1955- e incluir al decenio peronista. Como bien se sabe, el legado del peronismo es complejo y contradictorio: si bien en diversas esferas este supuso el arribo de sectores tradicionalistas y conservadores, también es posible encontrar en algunos ámbitos estatales - municipal, provincial o nacional - grupos profesionales que apostaban por algún tipo de transformación modernizadora. Desde allí se propiciaron una serie de políticas, propuestas y proyectos que —como la instalación de las fábricas automotrices, el Plan Regulador o el proyecto de la Ciudad Universitaria - implicaron una importante modernización de la estructura social y urbana de la ciudad, cuyo impacto se prolongaría — por lo menoshasta la década del setenta.

Sin pretender abordar todo el ciclo mencionado, en el presente trabajo nos proponemos indagar las diferentes políticas urbanas impulsadas en Córdoba durante el peronismo, atendiendo, por un lado, a los contextos pertinentes que las posibilitaron, y, por el otro, a los debates disciplinares del urbanismo y la arquitectura de las que se nutrieron. Para ello, nos centraremos en la figura del italiano Ernesto La Padula — quien, al poco de

1 Entre las principales referencias podemos mencionar: Gordillo, 1996. Brennan, 1996.

2 Considérese, por ejemplo, James, 2003. 
llegar a Córdoba, logró una rápida inserción en diversos ámbitos estatales desde donde participó en diversos emprendimientos urbano-arquitectónicos, convirtiéndose en una figura central de la arquitectura y el urbanismo en la ciudad - y en el Plan Regulador (PR) de su autoría. Ahora bien, ¿cuáles fueron las intervenciones urbanas impulsadas por el peronismo? ¿De qué manera se insertó La Padula en la nueva dinámica estatal abierta por este? Además, ¿en qué contexto, tanto local como nacional, se dio comienzo a los estudios para un PR en la ciudad? ¿Qué debates supuso? ¿Qué tipo de propuesta urbana tenía el Plan y cómo buscaba intervenir en la ciudad?

De forma sintética podríamos decir que si, como señala Anahí Ballent, ${ }^{3}$ el peronismo en Buenos Aires vino a completar y ampliar el ciclo de «modernización urbana» abierto en los treinta, en Córdoba, por el contrario, significó la apertura de un ciclo de transformaciones que se prolongó hasta mediados de los setenta. Esto se debió a que en su ensayo de reconfiguración estatal con eje en la planificación —que tuvo una importante repercusión en el manejo de la «cuestión urbana»—, el peronismo impulsó una serie de proyectos y propuestas de alto impacto en la ciudad, que si por un lado tendían a una modernización de la estructura urbana — como en el caso del PR-, por el otro, incorporaban al «patrimonio arquitectónico» como parte fundamental de ese proceso modernizador. Por otro lado, la trayectoria de La Padula en diversos ámbitos estatales de Córdoba — desde su llegada en 1949 hasta su regreso a Italia en 1964- aparece como un caso anómalo, en parte debido a su condición de extranjero y de «técnico». Esto le permitió asegurar la continuidad de los trabajos del PR — que bajo su dirección se prolongaron desde 1954 a 1958, siendo aprobados oficialmente en 1962 - al mantenerse al margen de las virulentas disputas políticas entre peronistas y antiperonistas; más aun, unos y otros recurrieron a él para diversos proyectos. En cuanto al PR, sostenemos que fue escrito cuando una nueva dinámica urbana de tensión entre el centro y la periferia ya estaba en funcionamiento, producto del fuerte crecimiento que experimentaba la ciudad desde principio de los cincuenta. A su vez, el PR se formuló en el contexto de un viraje del «urbanismo» y del «plan regulador» hacia las nociones de «planificación» y de «plan director» que, según Ana María Rigotti, implicaban el paso de una visión que buscaba intervenir en el espacio urbano por medio del proyecto arquitectónico, a otra más abstracta

3 Ballent, 2004, 316. 
y racional que, a partir de un «código urbano», regulaba la propiedad y el uso del suelo, las densidades y las actividades permitidas por zonas, y en el que, además, cobraba mayor fuerza la consideración, en diversas escalas, del problema del territorio y la «región». ${ }^{4}$ A mitad de camino entre uno y otro, el PR de La Padula se estructuraba sobre un diagnóstico de la ciudad y proponía una serie de líneas generales sobre el «código urbano» que debían desarrollarse, pero dejaba casi fuera de las consideraciones el tema de la región. Sobre la imagen de una Córdoba en transformación, La Padula trabajó sobre la hipótesis de que no había que modificar dicha dinámica, sino intervenir en ella a partir de una descentralización funcional de la ciudad, a tono con la tradición anglosajona de la «unidad vecinal». A pesar de ello y producto de la difícil aplicación del urbanismo en el país, el PR terminó reducido a una propuesta de esquema vial. Todo ello no impidió que las ideas urbanas de La Padula sirvieran como marco a partir del cual se pensaron las intervenciones en Córdoba hasta mediados de los setenta. Recién con el Diagnóstico tentativo y alternativa de desarrollo físico para la ciudad de Córdoba de María Elena Foglia de 1973 se propusieron nuevas hipótesis de crecimiento e intervención en la ciudad.

\section{Fascismo y arquitectura}

La Padula llegó a Córdoba gracias al proyecto de la «Ciudad Universitaria Presidente Perón» que había impulsado Miguel Urrutia durante su rectorado en la Universidad Nacional de Córdoba (UNC), como parte de un conjunto mayor de innovaciones, que incluía la creación de nuevas facultades - como la de Arquitectura- y la apertura del comedor universitario. Urrutia le encargó el proyecto a su amigo Ángel Lo Celso, decano de la Facultad de Ciencias Exactas Físicas y Naturales, que en junio de 1948 fue enviado al Primer Congreso de la Unión Internacional de Arquitectos que se realizó en Lausanne, Suiza. ${ }^{5}$ Allí se encontró con Marcello Piacentini, quien le recomendó a La Padula como «el arquitecto-urbanista más destacado de Roma», según sus palabras. ${ }^{6}$ Motivo suficiente para que Lo Celso contratara a La Padula para el proyecto de Ciudad Universitaria.

4 Respecto de la historia del urbanismo en la Argentina, sigo los planteos de Rigotti, 2012.

5 Libro de Sesiones del Honorable Consejo Directivo, sesión del 16 de junio de 1948, Archivo Facultad de Ciencias Exactas, Físicas y Naturales, UNC.

6 Ibidem, sesión del 5 de octubre de 1948. 
Para entonces, La Padula ya contaba con una destacada trayectoria en Italia. Antes de recibirse de doctor en Arquitectura por la Universidad de Roma en 1931, se había unido en 1928, como parte del «grupo romano», al Movimiento Italiano por la Arquitectura Racional (MIAR). Conviene precisar que la Italia fascista es un caso sumamente interesante para ver las complejas relaciones entre arquitectura y política. Así, mientras en Europa el desarrollo de la «arquitectura moderna» estuvo ligado al surgimiento de las vanguardias artísticas en la entre guerra, que luego fueron disueltas con el advenimiento del nazismo y el estalinismo en Alemania y la Unión Soviética, en Italia, por el contrario, el fascismo constituyó, según Diane Ghirardo, un importante impulso para el desarrollo de la arquitectura moderna, en tanto esta se pensó como un aporte propio y nacional, que contribuía desde su especificidad a la recreación de una cultura fascista, italiana y moderna. ${ }^{7}$ La constitución del MIAR en 1928 fue lo más cercano a una «vanguardia» arquitectónica en Italia, pero la misma no intentó un corte radical con el pasado y la tradición, sino que buscó una síntesis entre el legado italiano y las nuevas tendencias. ${ }^{8}$ Así, buena parte de los arquitectos racionalistas, como Guiseppe Terragni y Guiseppe Pagano, eran convencidos fascistas que tuvieron una buena acogida por parte del régimen. Esto permitió que dieran a conocer sus propuestas en dos exposiciones organizadas en 1928 y 1931 - a la primera de las cuales asistió el propio Mussolini- y que usaran los concursos de arquitectura para defender sus posiciones sobre la arquitectura y la ciudad. Aunque habían logrado algunos encargos estatales importantes - como la estación de trenes de Florencia o la Casa del Fascio de Terragni en Como-, la situación no les era enteramente favorable y las disputas con sus opositores declarados, el sector de los academicistas, fueron constantes.

Pero si bien el Estado fascista estuvo lejos de adoptar un estilo en particular, apoyando a distintos grupos arquitectónicos, lo cierto es que sí contó con una figura central que - aunque no fuera el «arquitecto oficial del régimen», como lo fue Albert Speer en la Alemania de Hitler— se convirtió en un cercano asesor de Mussolini y, desde esa posición, se postuló como un mediador entre las distintas tendencias arquitectónicas. ${ }^{9}$ Nos referimos a Marcello Piacentini ${ }^{10}$ quien, junto a Gustavo Giovanonni, fundó la revista

7 Ghirardo, 1992, 74.

8 Ghirardo, 1980. Tafuri y Dal Co, 1978.

9 Tafuri y Dal Co, 1978, 282.

10 Sobre la relación entre Piacentini y Mussolini véase Nicoloso, 2008, sobre todo el capítulo V. 
Architettura ed arti decorative la que, bajo el nombre de L'Architettura, se constituyó en el órgano oficial del Sindicato Nacional Fascista de Arquitectos. Además de diversos encargos, como la Ciudad Universitaria de Roma (1935) o el plan para la Exposición Universal de Roma de 1942 (EUR42), ofició de jurado en los principales concursos de arquitectura. Piacentini lideraba el grupo de los «moderados» que tenían asiento en Milán y Roma. Según Ghirardo,

en común con el grupo Novecento con base en Milán, los moderados romanos pensaron en simplificar y racionalizar el estilo académico en un intento de llegar a una síntesis italiana de lo moderno y lo tradicional, con el orden y la jerarquía externamente codificados en el edificio. El neo-clasicismo lombardo de uno de los moderados, Gio Ponti, ha sido correctamente caracterizado como de «progreso sin aventuras». Piacentini medió en las disputas entre los moderados y los academicistas, tanto como lo hizo entre estos dos grupos y los racionalistas, de este modo consiguió una posición central en la cultura arquitectónica del momento. ${ }^{11}$

En este contexto, La Padula se ganó el aprecio de Piacentini, según Massimiliano Casavecchia, ${ }^{12}$ con la Casa del Fascio de Taranto (1930), una de sus primeras obras, en la que se puede ver un buen ejemplo del énfasis sobre la «mediterraneidad» que expresaban algunos de los grupos racionalistas y que Piacentini apoyaba decididamente..$^{13} \mathrm{~A}$ lo largo de los años treinta, La Padula participó en los principales concursos de arquitectura, consiguiendo diversas menciones y premios. Entre los más destacados, podemos mencionar el concurso para el «Palacio del Littorio» (1934), el «Tribunal del barrio Aventino de Roma» (1933), «Casa Littoria» en Roma (1937), siendo el más importante de ellos el primer premio en el concurso para el Palazzo de la civilità italiana para la EUR42.

Uno de los mayores emprendimientos del régimen fascista, la EUR42 quedó oficializada en 1936, en el mismo momento en que Mussolini, tras haber conquistado Etiopía, declaraba el Imperio Italiano. Fue pensada como la «Roma de Mussolini», como una nueva ciudad representativa del régimen que incluía un moderno barrio modelo que extendería la vieja capital hacia el mar Mediterráneo, sobre el que Italia proyectaba su dominación. ${ }^{14}$ En 1937 se puso en funcionamiento una primera comisión integrada por Piacentini, Pagano, L. Piccinato, L. Vietti y E. Rossi que elaboró una

11 Ghirardo, 1980, 112 (traducción propia).

12 Casavecchia, 1986, 16-17.

13 Sobre la «mediterraneidad» en el debate italiano de los años treinta, véase Ghirardo, 1980.

14 Ciucci, 1995, 177 y ss. 
propuesta en base a un eje vial rodeado de edificios de acero, cemento y vidrio, que fue dejada de lado, en parte por los problemas de abastecimientos provocados por la guerra, asumiendo Piacentini la plena responsabilidad de una nueva propuesta unitaria del complejo. ${ }^{15}$ Según Manfredo Tafuri y Francesco Dal Co, esto implicó una «derrota» de los sectores más innovadores por un esquema mucho más rígido y monumentalista, expresada en la disposición axial de la exposición, lo cual no impidió la participación de los grupos racionalistas. ${ }^{16}$ Entre ellos estaba la propuesta de La Padula, Giovanni Guerrini y Mario Romano, en la que se mezclaban referencias historicistas — como la utilización del «arco romano»- con un juego volumétrico sobrio y despojado de toda ornamentación, en continuidad con la impronta «mediterránea» de parte del racionalismo italiano.

Al finalizar la guerra, Italia vivía una situación de crisis económica que propició una nueva ola migratoria hacia la Argentina, que incluyó a numerosos profesionales, ${ }^{17}$ entre ellos a La Padula, que aceptó la invitación de la Universidad Nacional de Córdoba para incorporarse al equipo para el proyecto de Ciudad Universitaria y para dictar la materia Composición Arquitectónica VI, permitiéndole, además, reencontrarse con su hermano gemelo, Cesar La Padula, quien había llegado en 1947 como profesor de ingeniería en electricidad. Si el proyecto de Ciudad Universitaria tuvo una corta vida, ya que los terrenos sobre los que se la pensaba construir fueron cedidos a la Fundación Eva Perón, La Padula se incorporó rápidamente al plantel de profesores de la Escuela de Arquitectura. La buena relación con Lo Celso le sirvió para que fuera incluido en la primera Comisión Redactora del PR propuesto en 1950.

\section{Peronismo y ciudad}

La Padula llegó en un momento muy particular de la ciudad y del país. Mientras el peronismo ensayaba una reconfiguración estatal, en Córdoba comenzaban a notarse los indicios de un proceso de «metropolización» que transformaría la ciudad en unos pocos años ${ }^{18}$ Desde finales de la década del cuarenta, es posible observar un importante incremento en las corrientes

15 Ibidem, 186.

16 Tafuri y Dal Co, 1978, 292.

17 Como Cino Calcaprina y Enrico Tedeschi. Véase Liernur, 1995.

18 Para un análisis general del proceso de urbanización: Malecki, 2015. 
migratorias que llevaron a que Córdoba duplicara su población entre 1947 y 1970, pasando 386.000 habitantes a casi 800.000 . Buena parte de esa nueva población fue absorbida por las fábricas automotrices y metalmecánicas, que llegaron a representar el $75 \%$ del total de trabajadores para 1961. Asimismo, desde los años cincuenta Córdoba fue densificando su centro, consolidando sus áreas intermedias y, a partir de los sesenta, vivió un crecimiento exponencial de sus áreas periféricas, donde se asentaron en forma mayoritaria las nuevas industrias y obreros. Así, en 1947 el área céntrica y los barrios tradicionales albergaban casi la mitad de las viviendas, mientras que las de las zonas periféricas representaban el 36,7 \%. Para 1960, la proporción se había invertido: en la zona tradicional se encontraba el 35,5\% de las viviendas, mientras que en los nuevos barrios se ubicaba el 47,9\%. Pero el centro también se transformaba, incorporando numerosos edificios de departamentos, lo que reflejaba el auge de las construcciones en altura. Lo que emergía como novedoso, además de su nuevo paisaje de edificios, era una dinámica de tensión entre el centro y la periferia.

Ahora bien, con la llegada del peronismo al poder en la provincia se impulsaron diversas intervenciones urbanas - algunas de las cuales no pasaron del papel, mientras que otras fueron terminadas muchos años después- que, en conjunto, supusieron importantes transformaciones de la ciudad. Ellas deben enmarcarse, además, en su intento por dotar al Estado de un conjunto de herramientas que permitieran intervenir en los diversos ámbitos de la vida nacional. Si bien la planificación ocupó un espacio central en la agenda política, sus logros fueron dispares y estuvieron sujetos a no pocos vaivenes políticos, que en el caso de Córdoba fueron particularmente problemáticos.

Según señala Cesar Tcach, la situación política de la provincia durante el decenio peronista fue de una constante inestabilidad. A las dificultades para unificar en el Partido Peronista las fuerzas que confluyeron en la candidatura de Perón —el Partido Laboral y la Unión Cívica Radical Junta Renovadora-, le siguió una intervención casi constante desde Buenos Aires al partido provincial, con la intención de encolumnarlo detrás de las directivas de Perón. La inestabilidad partidaria y la fuerte injerencia de Buenos Aires se trasladaron a la política provincial, contando con varias intervenciones federales entre 1947 y 1949, y una sucesión de gobernadores hasta 1955. Además, siguiendo la modificación de la Constitución nacional de 1949, se reformó la Carta Magna provincial ese mismo año. El dato que más nos interesa es que allí se eliminó la autonomía municipal de 
Córdoba, siendo el intendente designado directamente por el gobernador y quedando la Cámara de Diputados provincial como Consejo Deliberante de la ciudad. Justamente a partir de 1949, con la gobernación del Brigadier Juan San Martín, se inició una serie de reformas estatales - como la creación de nuevos Ministerios-, se procedió a elaborar un Plan de Obras Públicas (1949-1952) y se promulgó una ley de promoción industrial. Por otra parte, buena parte de la dirigencia peronista de la provincia provenía de los sectores tradicionales y conservadores de Córdoba, con estrechos vínculos con la Iglesia que, como en otras provincias, le dieron un temprano apoyo a Perón. ${ }^{19}$ Como veremos a continuación, el cruce entre los sectores políticos que conformaron el peronismo y los proyectos urbanos emprendidos por este generaron no pocos roces, en los que es posible advertir cómo viejas genealogías político-culturales - como aquellas que encontraban en el pasado colonial la principal impronta de Córdoba- podían entrar en tensión con sectores profesionales que pugnaban por acercar los desarrollos disciplinares del momento.

En mayo de 1950 el diputado provincial por el peronismo Alberto Novillo Saravia presentó la primera propuesta para un Plan Regulador para la ciudad de Córdoba. ${ }^{20}$ Hijo de Lisardo Novillo Saravia — rector de la universidad entre 1943 y 1945-, pertenecía, como su padre, a la élite tradicionalista de Córdoba, de fuerte raigambre católica, conservadora y anti reformista. Además de diputado, participó como convencional constituyente en 1949, en donde se mostró como un «ardiente pregón del clericalismo». ${ }^{21}$ El proyecto de Novillo Saravia proponía la creación de una «Comisión de Honorables» -integrada por representantes del Estado, de la universidad y personalidades destacadas - que trabajarían ad honorem..$^{22}$ En la fundamentación del proyecto, indicaba que la ciudad creció y se ensanchó sin orden ni plan y que para revertir esos problemas se debía considerar que «toda ciudad tiene, a semejanza del hombre, un cuerpo y alma», para señalar que

19 Tcach, 2006, 92 y 181.

20 Diario de Sesiones de la Honorable Cámara de Diputados actuando como Consejo Deliberante de la Capital, Legislatura de Córdoba (DSHCD), sesión del 2 de junio de 1950, asunto 18,165 .

21 Tcach, 2003, 44 y ss.

22 La comisión fue conformada en febrero de 1951 por el Ing. Luis Juárez Revol (director de control de obras privadas del MOP), Arq. Palmiro Vicente (delegado del Poder Ejecutivo provincial), Ing. Ángel Lo Celso (Facultad de Ciencias Exactas Físicas y Naturales), Arq. La Padula (Escuela de Arquitectura), Arq. Adolfo Vanni, Dr. Rafael Moyano López, Dr. Ricardo A. Galíndez, Ing. Ernesto Vicente y Arq. Eduardo Ciceri. Decreto 3.609 «A», Boletín Municipal, 2.719, Córdoba, 14 y 15 de febrero de 1951. 
«el estilo arquitectónico de Córdoba debe y tiene que ser el colonial». ${ }^{23}$ Por ello, la primera y principal tarea de la Comisión era la de reconstruir los «antecedentes históricos de la construcción urbana y formas tradicionales de su estilo». Con este trabajo, la Comisión debía elaborar un plan que incluyera: una «modernización» y un ordenamiento de los estilos, la ubicación de nuevos edificios públicos, la «formación de parques» y la búsqueda de una higienización en general. ${ }^{24}$ El proyecto de Novillo Saravia — quien tenía una formación en abogacía y no en arquitectura - retomaba tópicos muy generales que bien podrían estar asociados a la «estética urbana», propia del urbanismo decimonónico. Porque su autor provenía de un campo ajeno, el proyecto ignoraba completamente los debates contemporáneos que se estaban dando en el urbanismo del país, particularmente aquellos relativos a la reconstrucción de San Juan y los que se realizaron para el Estudio para el Plan de Buenos Aires (EPBA). Algunas de las propuestas allí presentadas encontraban en el urbanismo funcionalista de la «Carta de Atenas» del Congreso Internacional de Arquitectura Moderna (CIAM) su principal referencia. ${ }^{25} \mathrm{Si}$ bien la Comisión no tuvo actividad, le permitió a La Padula darse a conocer en diversos ámbitos estatales y ya para 1953 revestía como asesor técnico del Ministerio de Obras Públicas (MOP) y colaboraba asiduamente con el municipio.

Durante la intendencia de Martín Federico (1951-1954) se llevaron adelante diversos emprendimientos urbanos que tuvieron en La Padula a uno de sus principales artífices. Si el más destacado fue el PR, conviene detenerse brevemente sobre algunas de esas otras iniciativas que permiten apreciar ciertos ejes por donde se pensaron las intervenciones en la ciudad. La primera de ellas fue el llamado a concurso para el «Palacio Municipal». La iniciativa fue impulsada por Federico a comienzo de 1953. En febrero se firmó un convenio con la Sociedad Central de Arquitectos de Córdoba, aprobándose las bases del concurso en abril. ${ }^{26}$ En julio, la Cámara de Diputados aprobó la toma de un crédito por veinte millones de pesos para la construcción del «Palacio Municipal» (figura 1) que debía ser «un edificio administrativo sin pretensiones de asombrar ni maravillar», para «obtener oficinas limpias, iluminadas y aireadas para que el público y los empleados

23 DSHCD, sesión del 2 de junio de 1950, asunto 18, 165-166.

24 Ibidem, 165-171. Ordenanza Municipal 3.959, Boletín Municipal, 2.590, Córdoba, 1 y 2 de agosto de 1950.

25 Sobre estas discusiones véase Liernur y Pschepiurca, 2012.

26 Decreto 883, serie C, del 24 de febrero de 1953 y Decreto 1.033 del 20 de abril de 1954, Archivo de Gobierno (AG). Véase DSHCD, sesión del 22 de julio de 1953, asunto 3, 107. 
estén en un ambiente razonable». ${ }^{27} \mathrm{El}$ terreno elegido era un pequeño triángulo ocupado por edificios viejos, entre el arroyo La Cañada y el Paseo Sobremonte. En septiembre se sustanció el concurso, cuyo jurado estuvo integrado por La Padula, Federico, Raúl Zarazaga, Miguel Revuelta, Alberto Prebisch, Roberto Leiva y Alfredo C. Casares. El primer premio correspondió a la propuesta del Estudio de Arquitectura Santiago Sánchez Elía, Federico Peralta Ramos y Alfredo Agostini (SEPRA). ${ }^{28}$ El Estudio se había formado en 1936 y contaban con una sólida trayectoria, habiendo construido varios rascacielos en Buenos Aires a partir de la utilización del hormigón armado, mientras que en Córdoba ya habían proyectado el edificio para el Hospital Privado en 1950. La propuesta de SEPRA era de inspiración

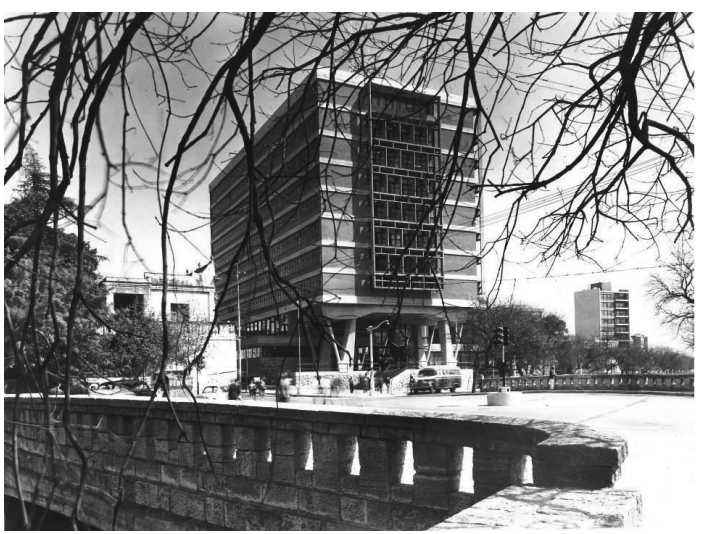

Figura 1. Palacio Municipal 6 de julio, proyecto del Estudio SEPRA. Fotografía: Manuel Gómez Piñeiro. lecorbusierana, con fuertes reminiscencias a la unité d'habitation de Marsella, que dotaba al nuevo edificio municipal de una clara estética moderna. Según Liernur, «la planta baja $[\ldots]$ fue organizada como un espacio en doble altura en el que [...] se destacaban los fuertes pies derechos, los núcleos de circulación y los entrepisos colgantes». ${ }^{29}$

A pesar de una recepción favorable al principio, ${ }^{30}$ el modernismo arquitectónico del proyecto despertó ciertas preocupaciones en algunos grupos católicos y conservadores que en octubre de ese año salieron en defensa del Paseo Sobremonte - contiguo al nuevo edificio-, en nombre de la tradición y el legado colonial, en el mismo momento en que comenzaba el distanciamiento entre la Iglesia y el peronismo. Pero esa

27 DSHCD, sesión del 22 de julio de 1953, asunto 3, 105-109.

28 Boletín Municipal, 3.272, 30 de septiembre y 1-4 de octubre de 1953.

29 Liernur, 2008, 268.

30 La Voz del Interior, 3 y 11 de octubre de 1953. Los Principios, 17 de septiembre y 3 de octubre de 1953. 
invocación a una tradición «colonial» podía resultar ambiguo, en tanto podía usarse para proponer una «modernización» urbana, que incluyera ordenación y embellecimiento, como en la propuesta del PR de Novillo Saravia, como para defender tradicionales valores estéticos contra las intromisiones modernistas del Palacio Municipal. Justamente, el problema se produjo porque el proyecto planteaba ciertas modificaciones al Paseo. Según expresaban los proyectistas, «con el objeto de que la composición resulte armoniosa y adquiera jerarquía y unidad, hemos suprimido la calle Bolívar y modificado el acceso al Palacio de Justicia, lo que nos permite, por medio de grandes terrazas y escalinatas, formar un conjunto de los edificios y el paseo». ${ }^{31}$

La polémica estalló en el diario Los Principios, de extracción católica. Con un editorial titulado «¿Debe destruirse el Paseo Sobremonte? Responden los muertos», Luis Roberto Altamira, del Instituto de Estudios Americanistas -institución que, desde los años veinte, venía realizando un importante trabajo de puesta en valor del pasado colonial-, se mostraba taxativo respecto a los cambios que se proponían en el Paseo: «para quienes reverenciamos la tradición de Córdoba, es muy doloroso aceptar en silencio la "modernización" del ya casi bisecular Paseo Sobremonte». ${ }^{32}$ Por su parte, el Dr. Rodolfo de Ferrari Rueda señalaba que Córdoba era la «capital argentina que posee los más importantes edificios de la época hispánica o colonial», pero que esta «fisonomía propia» estaba amenazada por la demolición cada vez más frecuente de sus monumentos. ${ }^{33}$ Menos propenso a apelar a la tradición para oponerse a las modificaciones, Santiago Beltrán Gavier proponía una «estética» que pudiera reconciliar pasado con futuro, preocupándose, además, por la pérdida de espacios verdes. ${ }^{34} \mathrm{Tal}$ fue el alboroto que el intendente salió a dar explicaciones a través del Boletín Municipal a los que «han expresado su preocupación ante lo que consideran un atentado contra la historia, la tradición, la cultura o el urbanismo». Ahí señalaba que el Paseo «ha perdido hace tiempo su verdadera fisonomía histórica», que «no expresa ninguna conexión con el pasado colonial ni antiguo». ${ }^{35}$ A pesar de las denuncias, el proyecto fue llevado adelante tal como se había planteado.

$31 \quad$ La Voz del Interior, 11 de octubre de 1953.

32 Los Principios, 27 de octubre de 1953.

33 Ibidem, 30 de octubre de 1953.

34 La Voz del Interior, 19 de noviembre de 1953

35 Boletín Municipal, 3.277, 31 octubre y 1-4 de noviembre de 1953. 
Una de las mayores apuestas edilicias del peronismo en la ciudad fue el proyecto para la «Sistematización Urbano Edilicia del Centro Administrativo de Córdoba», que debía incluir todas las dependencias de gobierno y del poder legislativo. La propuesta comenzó a gestarse en 1946, presumiblemente por iniciativa del ministro de Obras Públicas, Federico Francisco Weiss, y del director de Arquitectura, Carlos F. Lange. ${ }^{36}$ La iniciativa se encuadraba en un ambicioso plan de obras públicas de la Dirección de Arquitectura que incluía una nueva Central de Policía y Bomberos, el Consejo Provincial de Educación y una nueva sede para el Banco de Préstamos de la Provincia, obras que no se llevaron a cabo (figuras 2,3 y 4). ${ }^{37}$

En 1951 se sancionó una primera ley provincial que habilitaba al gobierno a vender diversas dependencias hasta el monto de ochenta millones de pesos. ${ }^{38}$ Recién en 1953 se aprobó la ley que creaba el «Centro Administrativo» y el nuevo edificio de la Legislatura, el primero en el sector en el que La Cañada se une con el Río Suquía, mientras que el segundo se encontraría en el sector sur de la Plaza Vélez Sarsfield, uno
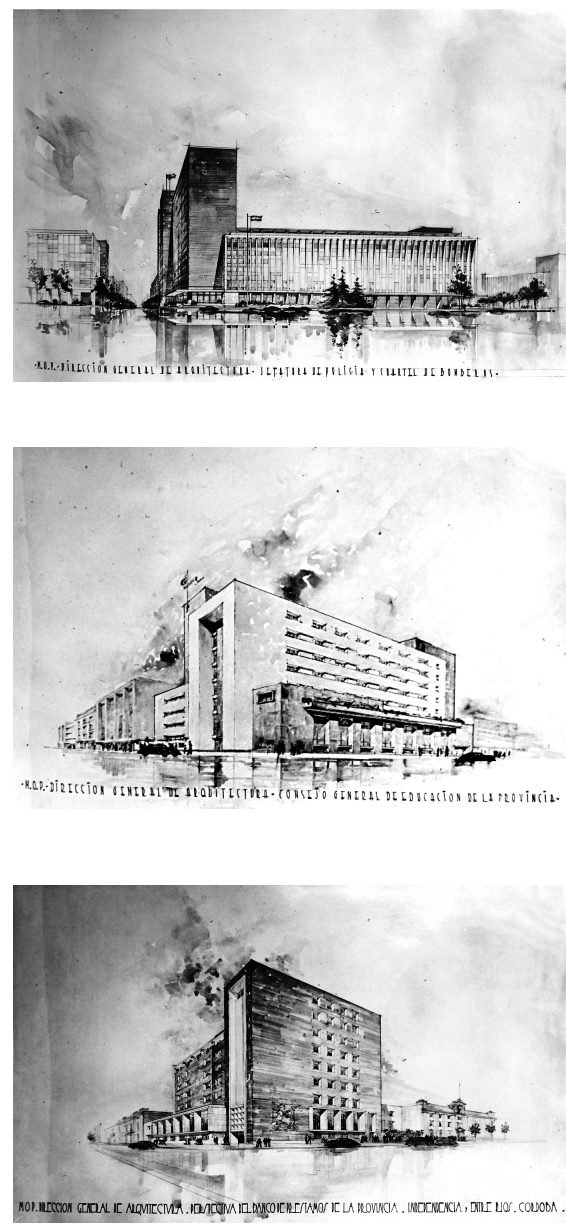

Figuras 2, 3 y 4 . Proyectos (no realizados) para la Jefatura de Policía y Cuartel de Bomberos, Consejo Provincial de Educación y Banco de Préstamos de la Provincia, respectivamente.

36 Decreto 4.012, serie C, 28 de octubre de 1946, AG.

37 La información y las fotografías de estos proyectos en Libro de Memorias del Ministerio de Obras Públicas de la Provincia de Córdoba, 1946/47, Archivo Histórico de la Legislatura Provincial. Lamentablemente los demás Libros de Memorias han desaparecido de los archivos consultados, por lo que no ha sido posible seguir su evolución.

38 Ley provincial 4.315, sancionada el 21 de diciembre de 1951. 


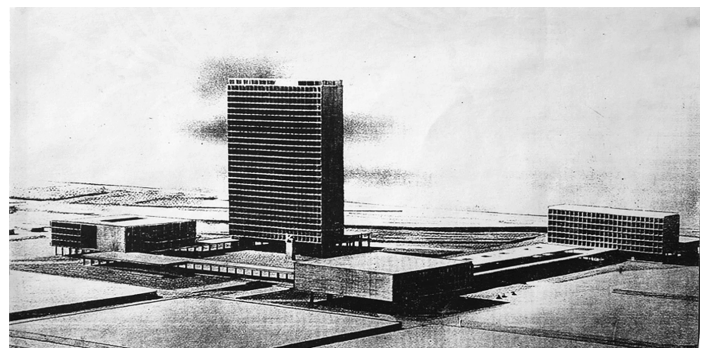

Figura 5. Proyecto ganador para el Centro Administrativo de la Provincia. Fuente: Archivo personal de Rébora. Gentileza de Gonzalo Fuzs. de los puntos simbólicos más importantes de Córdoba. ${ }^{39}$ Si bien no se avanzó en nada respecto de este último, en julio de 1954 se aprobaron las bases y el llamado a concurso para el Centro Administrativo que había elaborado La Padula en su carácter de asesor del MOP, integrando también el jurado..$^{40} \mathrm{El}$ concurso se sustanció en abril de 1955, resultando ganador el proyecto de los arquitectos Carlos Lange, Luis Rébora, Emilio Morchio, Mario Souberán y Antonio Bonet (figura 5). El mismo consistía en un gran edificio sobre pilotis que daba a una gran plaza seca rodeado de edificios menores que incluían diversos ministerios y dependencias gubernamentales, con una superficie estimada de $16.000 \mathrm{~m}^{2}$ (aunque en el debate legislativo se hablaba de 49.000 $\mathrm{m}^{2}$ ), que hubiera supuesto una intervención urbano-arquitectónica inédita en la ciudad ya que contemplaba toda un área a desarrollar. ${ }^{41}$

Según nos informó Alfredo Troilo ${ }^{42}$ — uno de los integrantes del equipo redactor del Plan Regulador reunido por La Padula en 1954-, sobre estas intervenciones puntuales - a las que habría que sumar la realizada en la catedral — La Padula pensó en estructurar un «recorrido verde» que hubiera ido de la Plaza San Martín, pasando por la Municipalidad y La Cañada, hasta el nuevo Centro Administrativo de la Provincia. De tal forma pensaba unir el «centro histórico» con los nuevos centros administrativo-gubernamentales. ${ }^{43}$

39 DSHCD, sesión del 26 de agosto de 1953, asunto 7, 1.179 y ss. Véase Ley 4.393.

40 Decreto 3.057, serie C, 28 de julio de 1954, AG. Dicho proyecto también suponía una superposición con la sistematización de La Cañada y una necesaria coordinación con la Municipalidad. A tales fines, fue también designado La Padula. Ver: Decreto 4.046, serie C, 23 de febrero de 1955; y Resolución 337, MOP, 24 de febrero de 1955, AG.

41 Para el gobierno provincial surgido del golpe de Estado de septiembre 1955, el proyecto del Centro Administrativo no resultaba una prioridad, señalando el gobernador de facto Comodoro Gallardo Valdéz que este no tenía «principio de realización inmediata». En cambio, sí se siguió trabajando sobre el Plan Regulador. La Voz del Interior, 21 de agosto de 1957.

42 Entrevista realizada por el autor a Alfredo Troilo el 5 de junio de 2013.

43 El único rastro que ha quedado de dicho proyecto son unas láminas realizadas $c a .1954$ por Mary Edith González, alumna de La Padula, que se encuentran en la Dirección de Planeamiento de la Municipalidad de Córdoba. 


\section{Modernización urbana y patrimonio arquitectónico}

Si la actuación de La Padula en los distintos emprendimientos urbanos que vimos implicó un decidido apoyo a propuestas que se encuadraban dentro de la arquitectura moderna, también hay que señalar que gracias en parte a sus gestiones se dio inicio a una importante recuperación del legado colonial arquitectónico en la ciudad. De esta forma, La Padula traía a Córdoba la particular articulación italiana entre modernismo arquitectónico y preservación arquitectónica, posicionando a la ciudad como una de las primeras del país en promulgar normativas edilicias específicas para la preservación del patrimonio arquitectónico y su entorno, mientras en Buenos Aires recién se aplicó una normativa similar recién en los setenta. Con esta iniciativa, además, La Padula sustraía la problemática del patrimonio del ámbito de los debates historiográficos en los que se había movido hasta entonces, para colocarla en los desarrollos disciplinares de la arquitectura, que tuvieron desde la década del setenta un impulso importante.

Con la sanción de la ley 12.665 en 1940, se creó la Comisión Nacional de Museos, Monumentos y Lugares Históricos, a cuya cabeza quedó uno de los exponentes de la «nueva escuela histórica», Ricardo Levene. Durante una primera etapa, en estrecha afinidad con la Academia Nacional de Historia, los criterios de la Comisión estuvieron ligados a los acontecimientos clasificados de excepcionales y se consideraba como monumento solo al ámbito físico de valor histórico o arqueológico. ${ }^{44}$ Las primeras declaraciones de monumento histórico por parte de la Comisión recayeron principalmente en Salta, Jujuy y Córdoba, incluyendo en esta la catedral, el cabildo, la iglesia y el convento de Santa Teresa, la casa del marqués de Sobremonte, entre otros. ${ }^{45}$ Estas iniciativas deben enmarcarse, en el contexto específico de Córdoba, en la configuración de un área de estudios coloniales que venía consolidándose desde, por lo menos, la década de 1910, en un intento de la élite local —según Ana Clarisa Agüero- por reconfigurar el lugar de Córdoba dentro de una geografía cultural dominada por Buenos Aires. Dichos estudios fueron llevados adelante por un conjunto heterogéneo de historiadores, coleccionistas, editores y arquitectos que dieron lugar a un nutrido conjunto de iniciativas que tuvieron como resultado una reconsideración del pasado colonial. «En efecto, lo decisivo de ese conjunto de "retornos

44 Sobre la historia del patrimonio arquitectónico en Argentina, véase Gandolfi y Silvestri, 2004.

45 Para un listado completo de los monumentos nacionales en Córdoba, consúltese http:// www.monumentosysitios.gov.ar/bienes.php. 
coloniales" fue el haber expuesto el pasado colonial menos como materia de juicio (el cual podía, eventualmente, ser aplazado) que como marca de una especificidad urbana recuperable y distintiva». ${ }^{46}$ La apelación a dicha marca resultó recurrente, sobre todo en los sectores tradicionalistas, según vimos en los debates sobre el primer proyecto de PR y en la controversia sobre el Palacio Municipal.

A pesar de lo expuesto, hasta las gestiones de La Padula dichos monumentos no habían tenido un cuidado especial, más allá de alguna obra de preservación, como en la casa del marqués de Sobremonte. En 1953 comenzaron una serie de disposiciones y trabajos que buscaron poner en valor el «centro histórico» de Córdoba, en los cuales La Padula tuvo un rol central. Si bien su concepción sobre el patrimonio todavía estaba atada a la idea del edificio como «monumento», es importante notar la introducción novedosa de una mirada sobre el «entorno urbano» que era deudora de las enseñanzas del italiano Gustavo Giovannoni, con quien La Padula se había formado en la Universidad de Roma. Una de las voces más autorizadas en el campo de la historia de la arquitectura italiana, Giovannoni, además, ocupó un rol destacado en los principales proyectos de intervención de los centros históricos de Italia durante los años veinte y treinta. ${ }^{47}$ Según ha señalado Françoise Choay, Giovannoni fue el primero en usar el término «patrimonio urbano» para indicar el elemento específico de «una doctrina original de urbanización», que otorgaba «simultáneamente a los conjuntos urbanos un valor de uso y un valor museal, integrándolos en una concepción general de la ordenación territorial». ${ }^{48}$ En Vecchie città ed edilizia nuova de 1931, sentó las bases de su aporte, en el que acuñó la metáfora con la que se conoció su teoría: el diridamento, que remite al despeje de bosques o de siembras densas para designar «la operación que sirve para eliminar todas las construcciones parásitas, agregadas o superfluas». ${ }^{49}$ Los trabajos emprendidos sobre la catedral de Córdoba dan cuenta de una aplicación, aunque sea parcial, de la teoría de Giovannoni. Conviene recordar que, hasta ese momento, la catedral estaba rodeada de viejas construcciones que no eran parte del edificio original. La preocupación de La Padula fue «despejar» a la iglesia de aquello que no le correspondía, además de darle un adecuado «entorno urbano» que no solo incluía sus alrededores inmediatos sino lo que era considerado el área histórica.

46 Agüero, 2012, 66.

47 Sica, 1981, 344.

48 Choay, 2007, 175.

49 Ibidem, 179. 
En noviembre de 1953 el intendente Federico mandó a la Cámara de Diputados un proyecto de ordenanza en el que se declaraba de interés público y sujeto a expropiación a los inmuebles comprendidos entre las calles Independencia, 27 de Abril, Obispo Trejo y Cuzco (actual pasaje Santa Catalina), moción que fue apoyada por peronistas y radicales, en tanto ambos compartían la apreciación del diputado Fox: «el centro mismo de la ciudad, su propio corazón, sufrirá una transformación que le dará una hermosa fisonomía colonial, enmarcando, para destacar ese cuadro, el Cabildo y la Iglesia de Santa Catalina». ${ }^{50}$ Promulgada la ordenanza, la municipalidad quedaba encargada de realizar una reestructuración edilicia de la manzana, para que quede «como espacio libre, conteniendo, exclusivamente, el edificio de la catedral». ${ }^{51} \mathrm{En}$ julio del año siguiente se creó una «Comisión Honoraria de Asesoramiento para la Sistematización y Restauración de la Manzana de la Catedral», compuesta, entre otros, por La Padula. ${ }^{52} \mathrm{Al}$ mismo tiempo se aprobaba una primera reglamentación que regulaba la altura de los edificios que daban a la plaza San Martín y sobre la avenida 27 de Abril, dejando librado a una aprobación municipal posterior el estilo arquitectónico.$^{53} \mathrm{La}$ ordenanza más importante fue la que establecía las líneas de edificación y las alturas máximas en las calles Deán Funes, 27 de Abril, Obispo Trejo e Independencia, la avenida Vélez Sarsfield y la plaza San Martín. El espacio que quedaba liberado con esta reglamentación estaba destinado a la ampliación de veredas y de espacios verdes, sobre los que La Padula pensaba el mencionado «recorrido verde». ${ }^{54}$ Finalmente, el convenio de expropiación entre el arzobispado y la municipalidad fue refrendado por la Cámara de Diputados el 31 de agosto de $1954 .{ }^{55}$

\section{El Plan Regulador de La Padula}

Volvamos ahora al contexto de gestación del PR de La Padula. Como indicamos, durante el peronismo se intentó generar una nueva dinámica estatal de fuerte intervención y planificación de la economía y de los sectores

50 DSHCD, sesión del 25 de noviembre de 1953, asunto 3, 335.

51 Ordenanza 4.238, Boletín Municipal, 3.287, 20-24 de diciembre de 1953.

52 Decreto 2.643, serie A, Boletín Municipal, 3.334, 30-31 de julio de 1954. El resto de la Comisión estaba compuesto por: el arzobispo de Córdoba, Juan D. Demarchi, y los arquitectos Arístides Saavedra Coria, Jaime Roca, Rafael Rodríguez Brizuela, Carlos Luque Colombres, Hugo Pelliza y Raúl Carranza.

53 Ordenanza 4.273, aprobada el 13 de julio de 1954.

54 Ordenanza 4.328, Boletín Municipal, 3.361, 18 de diciembre de 1954.

55 DSHCD, sesión del 31 de agosto de 1954, asunto 5. 
considerados estratégicos para el desarrollo del país. Según ha sido señalado en numerosos estudios, para llevar adelante dicha empresa el peronismo se valió de instrumentos que venían siendo desarrollados desde la década del treinta, aunque llevándolos a niveles y escalas no ensayados hasta entonces..$^{56}$ En este contexto, el urbanismo, en tanto manejo de la «cuestión urbana», recibió un impulso inédito en el Segundo Plan Quinquenal lanzado por Perón en 1952, que incluía un capítulo específico sobre la temática urbana, a pesar de que sus resultados fueron escasos. A diferencia del Primer Plan Quinquenal de 1947 que no había logrado articular claramente objetivos y estrategias, el segundo se estructuró a partir de capítulos bien definidos respecto de sus incumbencias y logros esperados. En el Capítulo VIII, Objetivo General 4, se establecía que el Estado Nacional impulsaría la «progresiva urbanización de todos los municipios y centros poblados del país mediantes planes reguladores», los que deberían tener en cuenta, entre otras cuestiones, «la descentralización y zonificación industrial», «la racionalización y coordinación de servicios públicos», etc. ${ }^{57}$ Además, la provincia adoptó este plan como propio, convirtiéndolo en el Plan Quinquenal Provincial en 1952. ${ }^{58}$

A la inclusión del urbanismo dentro de la planificación estatal, le siguieron una serie de iniciativas que buscaron generar las herramientas para que esos objetivos fueran llevados a cabo, como la modificación de los planes de estudios de arquitectura - con la incorporación de la ciudad y el urbanismo como problemática-, y la realización de encuentros de profesionales, como las jornadas realizadas en 1953 en Tafí del Valle (Tucumán) para discutir la planificación regional..$^{59}$ Por otro lado, para 1952 había numerosos planes reguladores publicados o en ejecución en Argentina. ${ }^{60}$ Aunque el único que tenía una explícita vinculación con el Segundo Plan

56 Véase, entre otros: Berrotarán, 2003. Ballent, 2005. Gaggero y Garro, 2009.

57 «Segundo Plan Quinquenal de la Nación Argentina. Texto completo del 2. do Plan Quinquenal (Ley 14.184)», Hechos e Ideas, Buenos Aires, 1954, 506-507.

58 Ley Provincial 4.364, 1952.

59 Facultad de Arquitectura y Urbanismo (FAU), 1953. Algunos de sus participantes fueron José Bonilla, Cino Calcaprina, José Pastor, Enrico Tedeschi y La Padula.

60 Los PR señalados por Rigotti son, entre otros: «Las bases para el Plan Regulador de JujuyPalpalá», de Jorge Vivanco; el «Estudio para el Plan Regulador de Tucumán», de Cino Calcaprina; el esquema de uso de la tierra del «Plan de Desarrollo del Pueblo de Darwin», de Bacigalupo, Comastri, Guidali, Kurchan, Riopedre y Ugart; el «Plan Regional de San Nicolás», de José Bonilla; el «Proyecto Urbanístico de Unidad Vecinal» dentro del «Plan Regulador de San Juan», de José Pastor; la «Urbanización de Punta Ballena» en Uruguay, de Antonio Bonet; el «Proyecto de urbanización del Bajo Belgrano», de Jorge Kurchan dentro del EPBA; y el «Plan Regulador de Bahía Blanca», de Miguel Conrado Roca. Rigotti, 2014, cap. 5 «Todos hablan del plan», 332-413. 
Quinquenal era el «Plan Director de Transformación de Rosario», dirigido por Alberto Montes. ${ }^{61}$ A ello le tendríamos que sumar el de La Padula, cuya puesta en marcha se dio en referencia explícita al Segundo Plan Quinquenal pero que, por haber sido terminado tiempo después, todavía no ha sido considerado como parte de este. ${ }^{62}$

En este contexto específico, la segunda iniciativa para desarrollar el PR de Córdoba provino del propio intendente Federico, que en julio de 1954 mandó su iniciativa al Legislativo. En esta, desaparecía la anterior «Comisión Redactora» y era el Departamento Ejecutivo municipal el encargado de formular el PR, para lo cual se estipulaba la posibilidad de establecer convenios con otras reparticiones públicas, contratar personal especializado y tomar el asesoramiento de la Comisión Asesora Técnica Edilicia. La falta de mayores precisiones sobre las bases y objetivos, así como el inciso C del artículo 2, que supeditaba toda ordenanza municipal a la redacción del PR, generó un encendido debate en la Cámara de Diputados, en el que el diputado radical Becerra llegó a sostener que se estaba entregando «la suma del poder público». ${ }^{63} \mathrm{La}$ aprobación de la iniciativa, enmarcada en el Plan Quinquenal nacional y provincial y en estrecho vínculo con el MOP, marcó la última instancia en que la competencia por la planificación urbana era asumida de forma compartida por municipio y provincia.

Teniendo en cuenta la presencia ya consolidada de La Padula tanto en el MOP como en la municipalidad, no llama la atención que se lo haya designado como director del equipo técnico redactor del PR en noviembre de $1954 .{ }^{64} \mathrm{El}$ equipo trabajó hasta mediados de 1958 , cuando fue formalmente disuelto. Si bien el PR ya estaba formulado en sus líneas generales en 1956 - cuando La Padula hizo una primera presentación en una conferencia en la FAU-, no fue aprobado por el MOP y la municipalidad hasta 1962, incluyéndose una reactualización de algunas estimaciones. Apenas producida la «Revolución Libertadora», La Padula fue confirmado en el puesto

61 Ibidem, 345.

62 Bustamante, 2010, es el único trabajo sistemático sobre el PR, pero no incorpora los contextos más generales que permiten explicarlo y no hace referencia al plan quinquenal.

63 DSHCD, sesión del 31 de agosto de 1954, asunto 6, 307. La autorización al Departamento Ejecutivo para la formulación del PR se promulgó como Ordenanza 4.307 en el Boletín Municipal, 3.360, Córdoba, 15 y 17 de octubre de 1955. Deberíamos señalar que, desde su puesta en funcionamiento hasta el golpe de septiembre de 1955, el PR funcionó como una instancia coordinadora de varias dependencias públicas, tanto provinciales como municipales, como en el proyecto de sistematización del río.

64 El equipo fue completado con Raúl Zarazaga, Hugo Pelliza, Alfredo Troilo y Raúl Ferreyra Centeno. Decreto 2.945, serie A, Boletín Municipal, 3.367, 9 y 12 de noviembre de 1954; Decreto 3.010, serie A, Boletín Municipal, 3.373, 28 y 30 de noviembre de 1954. 
de director del PR, señalando su permanencia en ámbitos estatales más allá del convulsionado contexto político. Tanto es así que ofició de asesor y de representante del Gobierno Provincial en las gestiones que desembocaron en el traspaso a la universidad de los terrenos en los que se estaba construyendo la Ciudad Universitaria de la Fundación Eva Perón. ${ }^{65}$ Así, el estudio y la aprobación del PR llevado adelante por La Padula atravesó diferentes contextos, signados por diversos signos políticos, sin mayores problemas y hasta con cierto presumible apoyo por parte de las cambiantes autoridades.

Llegados a este punto, debemos preguntarnos: ¿en qué consistió el PR? Para responder a esta pregunta es necesario distinguir los diferentes elementos que componen ese artefacto tan particular que es un plan regulador. Efectivamente, este no solo busca intervenir sobre la ciudad material y sus procesos heterogéneos, dentro de un conjunto de fuerzas que lo exceden ampliamente, sino que también construye una serie de representaciones sobre la ciudad y pone en juego un conjunto de valores sobre lo que esta debería ser y, por tanto, delinea un objeto del pensamiento. En tal sentido, el PR de La Padula contiene una imagen de Córdoba, como diagnóstico de su situación, maneja una serie de hipótesis sobre el rumbo que deberían tomar sus transformaciones y, por último, plantea una serie de intervenciones sobre la ciudad.

La imagen que traza La Padula en el PR es la de una ciudad que se encontraba inmersa en profundas transformaciones, que estaba pasando de ser «una pequeña aldea con calles de tierra» en la época de la colonia a ser la segunda ciudad del país, con nuevas edificaciones que sustituían a las viejas, llenándose antiguos baldíos, expandiéndose en la periferia: «mudos testigos de la sociedad indiana y de la vieja administración hispánica, sucumbieron ante la invasión de los comercios, de las casas de departamentos, y de oficinas, industrias y talleres». Pero esta situación, para La Padula, implicaba que Córdoba sufría una crisis, «la crisis de su crecimiento», producto de un «crecimiento anárquico», cuyo ritmo fue incrementándose hasta volverse «explosivo»: «en los últimos cuarenta años, Córdoba triplicó su población». Si este diagnóstico era compartido desde diversas miradas - como en la sociología de Juan Carlos Agulla o la geografía de Alfredo Terzaga - , para La Padula, en cambio, se trataba de la constatación de una nueva dinámica urbana de tensión entre el centro y la periferia: «es que Córdoba crece. Dilátese cuanto puede en los llanos y en las alturas, mientas

65 Sobre la ciudad universitaria, véase Malecki, 2013. 
su extensa periferia se vuelve anémica y su centro se congestiona». El resultado de todo ello era, para La Padula, un «cuadro dramático» que requería de la «urgente necesidad» de la planificación. ${ }^{66}$

Sobre esta imagen, entonces, La Padula trabajó sobre la hipótesis de que no había que revertir esa nueva dinámica de tensión entre centro y periferia, sino que había que retomar un «crecimiento orgánico» de la ciudad. Para ello, proponía el principio de una «descentralización racional de la ciudad y una "concentración orgánica" de los barrios que la componen». ${ }^{67}$ Antes de seguir avanzando, quisiéramos detenernos en las presuntas fuentes del urbanismo de La Padula y sus posibles relaciones con los debates en la Argentina.

La Padula, conviene recordarlo, había desarrollado alguna experiencia como urbanista en Italia, como con el PR para la zona norte de Ragusa (1936), el PR de reconstrucción de Rimini (1944-1945) o con el de Bracciano (1949). ${ }^{68}$ Italia, por otra parte, no tuvo durante los años treinta y cuarenta una contribución especial a los debates del urbanismo, incluso a pesar del fuerte impulso que el fascismo le dio al manejo de las ciudades y del territorio. Por ejemplo, en lo que se conoció como el «Agro Pontino» - una de las mayores empresas fascistas sobre el territorio-, que supuso la bonificación y colonización de los marjales Pontinos en los treinta. Allí se ensayaron propuestas que se acercaban a las Siedlung alemanas (Pomezia), al urbanismo académico (Pontinia) o al enfoque racionalista, como en el caso de Sabaudia, en la que participaron Gino Cancelloti, Eugenio Montuori, Luigi Piccinato y Alfredo Scalpelli que, si bien fue considerado como uno de los «puntos más firmes de la nueva cultura urbanística» italiana, no implicó una solución novedosa. ${ }^{69}$ De tal forma, Ludovico Quaroni podía afirmar en 1960 que la publicación de L'urbanística e l'avvenire della città de Giuseppe Samonà de 1959, era el «primer libro italiano de urbanismo» con el que se superaba la «infancia de los manuales». ${ }^{70}$ Por tanto, no debería sorprendernos, primero, que las principales referencias de La Padula remitan a los debates ingleses de la década del cuarenta y del cincuenta, con un fuerte énfasis en la tradición de la «ciudad jardín» y

66 La Padula, 1963, 747, 746, 747 y 756, sucesivamente.

67 La Padula, 1956, 24.

68 La información la hemos extraído del CV de La Padula que hemos encontrado en la Facultad de Filosofía y Humanidades de la Universidad Nacional de Córdoba. Lamentablemente no hemos podido acceder a sus propuestas urbanísticas.

69 Sica, 1981, 365.

70 Quaroni, 1960, 19 (traducción propia). 
su deriva en las «unidades vecinales» y, segundo, que su principal escrito sobre urbanismo haya sido un manual confeccionado para sus clases en Córdoba, que se dividía en tres partes: una aproximación histórica, un compendio sobre «elementos constitutivos de la estructura urbana» y un glosario sobre «composición urbana».

Si tenemos en cuenta, entonces, el análisis histórico sobre la evolución de las ciudades que traza La Padula en sus apuntes de cátedra, tendremos una imagen más precisa sobre su postura frente al urbanismo. Más aun, aquella imagen sobre Córdoba debiera ser inscripta en su lectura más amplia sobre las ciudades europeas. Así, La Padula sostenía que «la ciudad se dilata, pero su crecimiento no gana en velocidad al acrecentamiento de los hombres que quieren habitarla», produciendo en las «periferias» todo tipo de amontonamientos, en los que los nuevos loteos se repiten sin límite ni coordinación, cuyo «damero elemental es asumido como ejemplo de modernidad y repetido sin límites». Para los comienzos del siglo XX, «los barrios se extendían en sucesivos anillos concéntricos en torno a los viejos núcleos». La conclusión que extraía era que debía ponerse fin al «proceso monocéntrico de indefinido acrecentamiento, portador de desequilibrios y desarmonía». ${ }^{71}$

Ante este panorama, La Padula rescataba una serie de respuestas que, de Ebenzer Howard y Camilo Sitte a Lewis Mumford, constituyen lo que Françoise Choay ha llamado el modelo del «urbanismo culturalista». ${ }^{72}$ Para La Padula, la «verdadera gran luz» del urbanismo de principios del siglo XX fue Howard y su libro La ciudad jardín del mañana, en la que se producía un «feliz enlace entre ciudad y campo» ${ }^{73}$ que, prolongándose en los desarrollos del urbanismo inglés, logró la «concepción de una vasta descentralización en unidades satelitales armónicamente coordinadas entre ellas». El manual también aportaba planos de reformas urbanas - de Haussmann a las diversas variantes del urbanismo moderno (Wright, Aalto, Le Corbusier, Sert, etc.)—, de las cuales habría que destacar la inclusión de las propuestas para la descentralización de Chicago y Helsinki de Eliel Saarinen, en la que indicaba que la Carta de Atenas «no soluciona» todos los problemas de urbanismo actual, y que las teorías del finlandés «abren inesperadas posibilidades» para solucionar los problemas que presentaban las ciudades exis-

71 La Padula, 1957, Primera Parte, 89-91.

72 Choay, 2006.

73 La Padula, 1957, Primera Parte, 93. 
tentes. ${ }^{74}$ Saarinen, en La ciudad de 1943, reconocía que la «centralización» de funciones y la «descentralización» poblacional operaban en las ciudades como dos fuerzas históricas centrífugas que, dejadas a su suerte, generaban los problemas de la ciudad moderna. Advirtiendo del «desordenado crecimiento de la ciudad de ayer», proponía una «descentralización orgánica» que, en base a «principios de flexibilidad y protección», operaran en la «concentración de las condiciones de habitación y trabajo del individuo, y descentralización de los diversos grupos de actividades de la ciudad». ${ }^{75}$

La referencia a Saarinen es importante porque es uno de los principios que articula el PR de La Padula, en el que se proponía la transformación de «la ciudad en una constelación de barrios, dotados de suficiente autonomía, para disminuir la presión que hoy ejercen sobre la zona central», ${ }^{76}$ entendiendo que en esos barrios «se admitirían oportunamente núcleos residenciales de carácter obrero, de acuerdo con las modernas tendencias que aconsejan una orgánica distribución de la población según las actividades que desempeñan los diferentes sectores sociales». ${ }^{77}$ Más aun, en sus clases proponía substituir la idea de una expansión monocéntrica de las ciudades por una que distribuyera periféricamente «nuevas "unidades suburbanas autónomas", concentradas entre sí y con el núcleo central, mediante arterias de tránsito ubicadas entre estos núcleos» ${ }^{78}$ Por esas razones, en el PR se establecía que la estructura de la ciudad estaría constituida por las rutas de acceso ${ }^{79}$ a partir de las cuales se articularía el sistema vial y un sistema de espacios verdes, y se dispondrían los edificios relacionados a las necesidades de la población, para «permitir la anhelada autonomía de los barrios urbanos y de sus unidades vecinales» (figura 6). ${ }^{80}$

Por las referencias señaladas, La Padula toma la idea de las «unidades vecinales» de los debates anglosajones de entreguerras, que se prolongaron en el Plan para la reconstrucción de Londres de Forschaw y Abercombrie de 1943. Según Sica, en la tradición de los new towns abierta por Howard, el neighborhood plannig fue desarrollado bajo la hipótesis de la cooperación interclasista. En los años veinte, Clarence A. Perry definió el concepto de «unidad vecinal» según la localización de un conjunto de «funciones

74 Ibidem, Tercera Parte, 29.

75 Saarinen, 1965, 132, 129 y 174, respectivamente.

76 La Padula, 1956, 23; 1963, 759.

77 La Padula, 1956, 24.

78 La Padula, 1957, 23.

79 La Padula, 1956, 19.

80 Ibidem, 26. 
sociales» que respondían a la vida cotidiana de la familia — escuela, parques, residencia, playgroudns, pequeñas tiendas- . De tal forma, «para sus defensores más convencidos, el barrio autónomo no es solamente un instrumento organizativo elemental, sino [...] también un principio de organización y estructuración formal de toda la metrópoli». ${ }^{81}$

Ahora bien, estas referencias de La Padula no eran novedosas en el contexto argentino. Para mediados de los cincuenta, la temática de la descentralización de las ciudades ya tenía una amplia difusión en el país y el modelo de las ciudades jardín y de la «unidad vecinal» había sido ensayado, o propuesto, en varias oportunidades, incluyendo el PR de Benito Carrasco para Córdoba en 1927. Uno de los principales impulsores de estas ideas en los cuarenta fue José Pastor desde la Revista de Arquitectura, órgano de difusión de la Sociedad Central de Arquitectos y del Centro de Estudiantes de Arquitectura, del que fue colaborador y secretario de redacción entre 1947 y 1951. Desde esa revista, Pastor se dedicó a la «difusión pedagógica de los principios del planeamiento regional en la versión humanista de Lewis Mumford y de las realizaciones del planeamiento anglosajón». ${ }^{82}$ En tal sentido, nos interesa destacar la cercanía entre las propuestas urbanas de Pastor y de La Padula, en tanto pertenecían a un mismo sistema de pensamiento donde la unidad vecinal tenía un lugar destacado. Así, por un lado, la divulgación por parte de Pastor de una serie de notas que desglosaban la cuestión de la «unidad vecinal» y de las «formas urbanas» recurría a los mismos ejemplos y diagramas que los utilizados por La Padula. ${ }^{83}$ Por otro lado, no deja de llamar la atención la similitud entre los planos para la reconstrucción de San Juan de Pastor y la del PR para Córdoba, que tenían en común su articulación en base a la idea de «unidades vecinales» y su propuesta de zonificación. Es difícil establecer si La Padula tuvo conocimiento de los trabajos de Pastor - y si fue así, si tuvieron alguna influencia en los suyos - , pero lo cierto es que el italiano tuvo una presencia reducida en los debates locales. Hasta donde ha sido posible indagar, La Padula asistió al ya referido encuentro en Tafí del Valle, a lo que podemos sumar su asistencia al «Primer Congreso Argentino de Planeamiento y Vivienda» realizado en

81 Sica, 1981, 177.

82 Gorelik, 2004, 46.

83 Por ejemplo: «Formas urbanas. Unidades vecinales», Nuestra Arquitectura (NA), 202, Buenos Aires, mayo de 1946, 154-159; «Anatomía de la unidad vecinal», NA, 205, agosto de 1946, 286-292; «Formas urbanas. El trazado de ciudades», NA, 211, febrero de 1947, 48-55; «El trazado viario y la cuestión de la tierra», $N A, 212$, marzo de 1947, 101-108; «El trazado viario, infraestructura tecnológica del plan nacional», $N A, 215$, junio de 1947, 194-198. 
octubre de 1957 en Tucumán, ${ }^{84}$ y una invitación de Jorge Ferrari Hardoy para La Padula y Lázaro Devoto para que asistan a Rosario para discutir «la necesidad de unificar los Institutos de Urbanismo y de Arquitectura», ${ }^{85}$ en el marco del desarrollo del Instituto de Arquitectura y Planeamiento de la Universidad de Rosario que dirigía Ferrari Hardoy. En 1964, aprobado el plan, muerto su hermano gemelo en 1959, La Padula decidió su regresó a Italia, en donde murió en 1968.

Pero volvamos nuevamente sobre el PR. En base a estas consideraciones podemos decir que este definía una serie de cuestiones en torno a «la ciudad futura» que aseguraran un «desarrollo orgánico» de la ciudad. Aquí conviene distinguir entre los aportes específicos de La Padula de algunas consideraciones muy generales - como las propuestas de densificación por áreas y una zonificación para la industria- ${ }^{86}$ de otras iniciativas que, si bien contempladas en el PR, en rigor eran anteriores a este y, de hecho, terminaron de concretarse muchos años después. Respecto de las contribuciones de La Padula, hay que destacar, en primera instancia, su contribución a formar una imagen sobre las transformaciones de Córdoba que venía a reforzar la que desde otras disciplinas se estaba realizando, como en la sociología, la geografía y las ciencias económicas. En segundo lugar, los dos elementos del PR que implicaron una intervención directa sobre la ciudad fueron, por un lado, la Ciudad Universitaria de la UNC, en uno de cuyos antecedentes ya vimos trabajar a La Padula, incluida como parte orgánica del PR, convirtiéndose en la única instancia que dio lugar a una intervención urbana, concretada con el Concurso Nacional de Planificación de 1962. Por otro lado, una propuesta de reordenamiento vial de la ciudad que contemplaba tanto las rutas de ingreso/egreso cuanto las principales arterias de circulación interna que comenzaron a ampliarse en los sesenta, así como también un sistema de tres anillos de circunvalación -interno, intermedio y externo-, del que solo llegó a realizarse el último. Según La Padula, «el anillo externo, con su cintura de verde, constituirá un verdadero elemento destinado a oponerse a una desmedida expansión urbana que perjudicaría la economía general de la ciudad». ${ }^{87}$ El largo trayecto en la construcción

84 Nuestra Arquitectura, 338, Buenos Aires, enero de 1958, 40-51.

85 Resolución Decanal 76/59, Exp. 813-L-59, Archivo Facultad de Arquitectura y Urbanismo, UNC.

86 La densificación proponía: centro 500 habitantes por hectárea, semiperiférica 110, periférica 85 , núcleos satélites 65 , zonas de las industrias auxiliares y barrios obreros 50 y zonas rurales y semirurales 10 .

87 La Padula, 1956, 21 

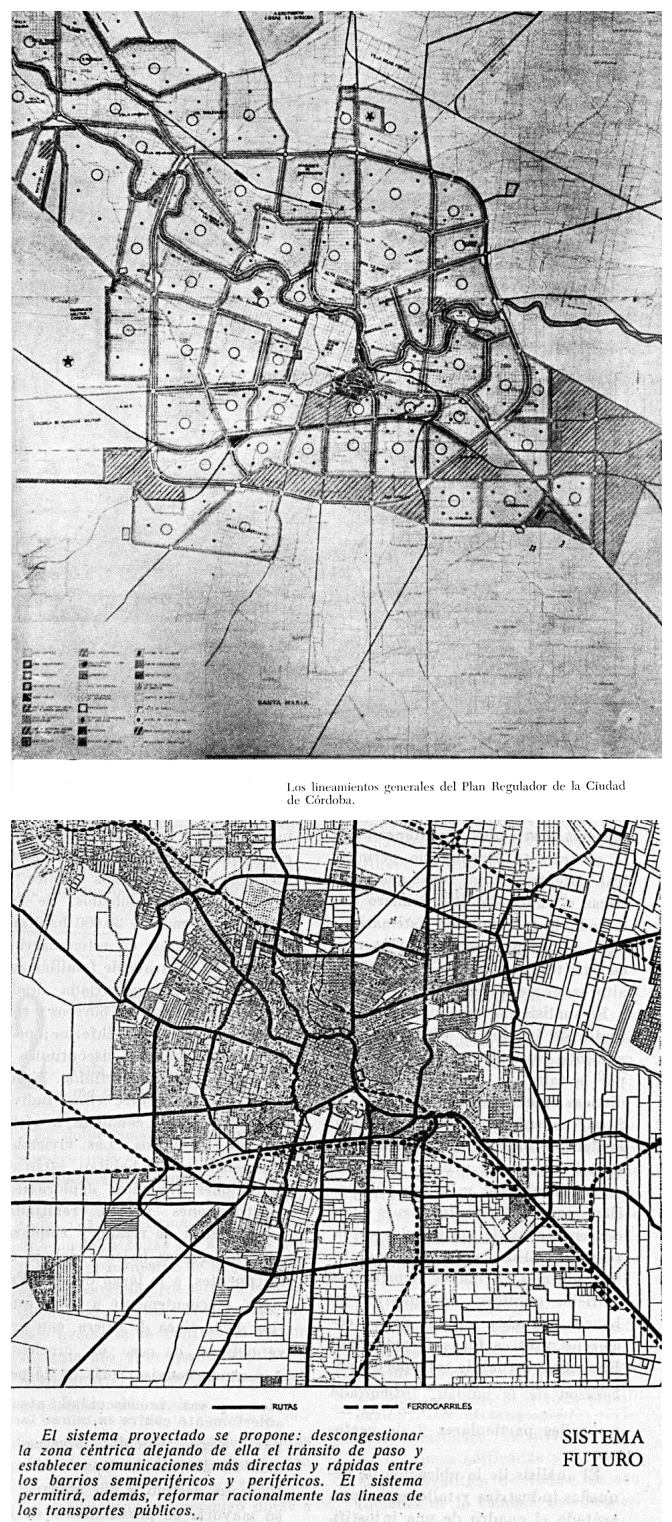

Figuras 6 y 7. Propuesta de zonificación según esquema de unidades vecinales y propuesta de remodelación de la estructura vial de la ciudad. Fuente: La Padula, 1963, s/n. de la circunvalación —cuyas primeras disposiciones para construirla son de 1966, comenzando sus obras unos años después y que todavía no ha sido terminada-, muestran las debilidades del Estado para llevar adelante emprendimientos de largo alcance (figura 7).

Por último, el PR incorporó una serie de emprendimientos que ya venían siendo desarrollados en distintas dependencias estatales desde unos años antes y que terminaron de concretarse muchos años después de aprobado el plan. La primera de ellas fue la sistematización del Río Primero (hoy Suquía), que venía siendo trabajada por la Dirección de Hidráulica y el MOP desde, por lo menos, 1949. En 1950 se aprobó una ley que declaraba de interés público los terrenos colindantes al río que serían afectados a la sistematización. En 1951 se conformó una Comisión Asesora intergubernamental encargada de confeccionar una lista de propiedades y viviendas a ser afectadas al proyecto y en ese año comenzaron las expropiaciones. Recién en 1955 se presentó un plan integral realizado entre 
el MOP y el Equipo Técnico del PR. ${ }^{88}$ En 1965 las obras de encauzamiento del río estaban bastante avanzadas y para 1970 ya se había confeccionado el esquema general de las avenidas que correrían paralelas al río, las que comenzaron a realizarse recién en los ochenta. La segunda es la ubicación de la nueva terminal de ómnibus que había sido establecida en la ley 4.394 de 1953, pero que recién se construyó en 1970. Finalmente, respecto de la zonificación industrial propuesta en el PR, hay que destacar que las industrias automotrices se asentaron antes de su formulación, siguiendo criterios económicos y de disponibilidad de tierra ${ }^{89}$ Estos ejemplos muestran los tiempos propios de la ciudad, en el que a unas erráticas políticas urbanísticas del Estado se le suman las dificultades de generar los mecanismos para hacer efectiva la intervención estatal, poniendo de manifiesto la distancia entre pensar la ciudad y su concreta materialización.

\section{Conclusiones}

La trayectoria de La Padula por diversos ámbitos estatales — provincial y municipal - nos permitió analizar un momento muy particular de Córdoba. Efectivamente, al tiempo que la ciudad comenzaba a mostrar los signos de un intenso crecimiento demográfico y urbano, el peronismo en el poder ensayaba una reconfiguración estatal que tuvo un resultado dispar. $\mathrm{Al}$ avanzar sobre un área poco estudiada por la historiografía local — como las políticas urbanas del primer peronismo y la historia urbana de Córdoba- fue posible dar cuenta de un conjunto de iniciativas e intervenciones que resultaron centrales para poder comprender el posterior desarrollo de la ciudad. El PR o el Palacio Municipal, por nombrar los dos más importantes, no solo se propusieron modernizar la estructura urbana de Córdoba, sino que también contribuyeron a cambiar su fisonomía. Al mismo tiempo, estos proyectos permiten apreciar lo heterogéneo que pueden resultar los equipos profesionales que actúan en el estado y el grado de conflicto que pueden generar con diversos sectores políticos. Así, por ejemplo, La Padula llevó adelante emprendimientos que entraban en tensión con lo que algunos sectores afines al peronismo entendían que era la tradición colonial de Córdoba.

88 Véase, respectivamente: Ley provincial 4.266, 31 de agosto de 1951; Decreto 18.309, serie C, 31 de enero de 1951; Decreto 18.773, serie C, 16 de febrero de 1951; Decreto 4.046, serie C, 23 de febrero de 1955, AG.

89 Cecchetto, 1988. 
Pero justamente la figura de La Padula permite complejizar la mirada respecto a las relaciones entre política y arquitectura. No solo porque logró esquivar con notable éxito las disputas entre peronistas y antiperonistas, sino porque con sus iniciativas sobre el centro histórico lograba una intervención en la ciudad material en la que, al tiempo que consolidaba la noción de patrimonio arquitectónico, lo incorporaba como parte necesaria dentro del proceso de modernización de la estructura urbana. De tal forma, la articulación entre patrimonio y modernidad a la que había contribuido $\mathrm{La}$ Padula permitía, por un lado, desarticular —o por lo menos desestabilizarla antinomia entre tradición y modernidad que tanto los sectores católicos como los que se identificaban con la Reforma del 18 habían entendido como rasgo distintivo de Córdoba, al tiempo que, por otro lado, esa articulación fue usada, también, en un amplio conjunto de imágenes - producidas durante los sesenta y setenta — para dar cuenta de la aceleración de los tiempos históricos que el proceso de modernización urbana estaba produciendo. Por otro lado, el PR muestra hasta qué punto la modernización urbana podía ser compartida por diferentes grupos políticos, pero ese supuesto consenso también señala las dificultades de sostener políticas de largo plazo.

Recibido el 18 de abril de 2016 Segunda versión el 19 de septiembre de 2016 Aceptado para publicar el 3 de octubre de 2016

\section{Referencias bibliográficas}

Agüero, Ana Clarisa, «Comunidades, circuitos y lugares relativos en la cultura nacional. Caída y reparación de Córdoba entre dos generaciones (1880-1920)», en Laguarda, P. y Fiorucci, F. (eds.), Intelectuales, cultura y política en espacios regionales de Argentina (siglo XX), Rosario, Prohistoria, 2012, 55-78.

Ballent, Anahi, «Perón en "la ciudad sin esperanzas". La política y las políticas urbanas en Buenos Aires», en Berrotarán, P.; Jáuregui, A. y Rougier, M. (eds.), Sueños de bienestar en la Nueva Argentina. Estado y políticas públicas durante el peronismo 1946-1955, Buenos Aires, Imago Mundi, 2004, 301-326.

Ballent, Anahi, Las huellas de la política. Vivienda, ciudad, peronismo en Buenos Aires, 1943-1955, Buenos Aires, UNQ, 2005.

Berrotarán, Patricia, Del plan a la planificación. El Estado durante la época peronista, Buenos Aires, Imago Mundi, 2003.

Brennan, James P., El cordobazo. Las guerras obreras en Córdoba, 1955-1976, Buenos Aires, Sudamericana, 1996 
Bustamante, Juana, «La figura del arquitecto italiano La Padula», en Ave, G. y De Menna, E. (eds.), Arquitectura y urbanística de origen italiano en Argentina. Tutela y valoración de un increíble patrimonio cultural, Roma, Gangemi, 2010, 113-127.

Casavecchia, Massimiliano (ed.), Ernesto B. La Padula. Opere e scritti, 19301949, Venecia, Cluva Editrice, 1986.

Cecchetto, Gabriela, Evolución de los asentamientos industriales IKA y FIAT. Su inserción en el espacio urbano cordobés. Un estudio comparado (19551968), Informe presentado al Consejo de Investigaciones de Córdoba (CONICOR), Córdoba, 1988, inédito.

Choay, Françoise, L’urbanisme, utopies et réalités, Paris, Éditions du Seuil, 2006.

Choay, Françoise, Alegoría del patrimonio, Barcelona, Gustavo Gili, 2007.

Ciucci, Giorgio, Gli architetti e il fascismo. Architettura e città 1922-1944, Turín, Einaudi, 1995.

Facultad de Arquitectura y Urbanismo, Votos de las jornadas de urbanismo. Tafí del Valle 1953, Tucumán, Boletín 2, 1953.

Gaggero, Horacio y Garro, Alicia, Mejor que decir es hacer, mejor que prometer es realizar. Estado, gobierno y políticas sociales durante el peronismo (19431955): proyectos y realidades, Buenos Aires, Biblos, 2009.

Gandolfi, Fernando y Silvestri, Graciela, «Patrimonio», en Liernur, J. F. y Aliata, F. (comps.), Diccionario de Arquitectura en la Argentina, Buenos Aires, Clarín, 2004.

Ghirardo, Diane, «Italian Architects and Fascist Politics: An Evaluation of the Rationalist's Role in Regime Building», Journal of the Society of Architectural Historians, 39, 2, Chicago, 1980, 109-127.

Ghirardo, Diane, «Architects, Exhibitions and the Politics of Culture in Fascist Italy», Journal of Architectural Education, 45, 2, 1992, 67-75.

Gordillo, Mónica, Córdoba en los 60: experiencias del sindicalismo combativo, Córdoba, UNC, 1996.

Gorelik, Adrián, «Pastor, José M. F.», en Liernur, J. F. y Aliata, F. (comps.), Diccionario de Arquitectura en la Argentina, Buenos Aires, Clarín, 2004.

James, Daniel (dir.), Violencia, proscripción y autoritarismo, Tomo IX, Nueva Historia Argentina, Buenos Aires, Sudamericana, 2003.

La Padula, Ernesto, «Lineamientos del Plan Regulador de la ciudad de Córdoba», Cuadernos de la Facultad de Arquitectura y Urbanismo, 1, Córdoba, 1956.

La Padula, Ernesto, Urbanismo, Córdoba, UNC, 1957.

La Padula, Ernesto, «Orden y destino de la ciudad de Córdoba», Revista de la Universidad Nacional de Córdoba, IV, 3/4, Córdoba, 1963, 745-760.

Liernur, Jorge Francisco, «Architetti italiani nel secondo dopoguerra nel dibattito architettonico della "nuova Argentina" (1947-1951)», Metamorposi. Quaderni di Architettura, 25/26, Roma, 1995, 71-80. 
Liernur, Jorge Francisco, «Un estudio de la sede del Banco de Londres y América del Sur. Buenos Aires, 1960-1966», en Liernur, J. F., Trazas de futuro. Episodios de la cultura arquitectónica de la modernidad en América Latina, Santa Fe, UNL, 2008, 261-277.

Liernur, Jorge Francisco con Pschepiurca, Pablo, La red austral. Obras y proyectos de Le Corbusier y sus discípulos en la Argentina (1924-1965), Buenos Aires, UNQ, 2008.

Malecki, Juan Sebastián, «Espacios de mediación: la Ciudad Universitaria de Córdoba, 1949-1962», Registros, 11, Mar del Plata, 2013, 20-39.

Malecki, Juan Sebastián, «La ciudad dislocada. El proceso de urbanización en la ciudad de Córdoba, 1947-1970», Cuadernos de Historia. Serie Economía y Sociedad, 13/14, Córdoba, 2015, 195-227.

Nicoloso, Paolo, Mussolini architetto. Propaganda e paesaggio urbano nell'Italia fascista, Turín, Einaudi, 2008.

Quaroni, Ludovico, «L'avvernire della città», Casabella continuità, Milán, 236, 1960.

Rigotti, Ana María, «Las promesas del urbanismo como alternativa tecnocrática de gestión (1928/1958)», en Plotkin, M. B. y Zimmermann, E. (comps.), Los saberes del Estado, Buenos Aires, Edhasa, 2012, 159-184.

Rigotti, Ana María, Las invenciones del urbanismo en Argentina (1900-1960). Inestabilidad de sus representaciones científicas y dificultades para su profesionalización, Rosario, UNR Editora, 2014.

Saarinen, Eliel, La ciudad: su crecimiento, su declinación y su futuro, México, Limusa, 1965.

Sica, Paolo, Historia del urbanismo. El siglo XX, tomo III, Madrid, Instituto de Estudios de Administración Local, 1981.

Tafuri, Manfredo y Dal Co, Francesco, Arquitectura contemporánea, Madrid, Aguilar, 1978.

Tcach, César, «Obreros rebeldes, sexo y religión en el origen del peronismo cordobés», en Macor, D. y Tcach, C. (eds.), La invención del peronismo en el interior del país, Santa Fe, Editorial UNL, 2003, 33-56.

Tcach, César, Sabattinismo y peronismo. Partidos políticos en Córdoba (19431955), Buenos Aires, Biblos, 2006. 